\title{
Optimization and Characterization of Nano Aluminum Trihydrate-Based Flame-Retardant Materials in the Rotating Packed Bed Reactor
}

\author{
Pao Chi Chen*, Ling Chun Yang \\ Department of Chemical and Materials Engineering, Lunghwa University of Science and Technology, Taiwan \\ Email: *chenpc@mail2000.com.tw
}

How to cite this paper: Chen, P.C. and Yang, L.C. (2018) Optimization and Characterization of Nano Aluminum Trihydrate-Based Flame-Retardant Materials in the Rotating Packed Bed Reactor. Materials Sciences and Applications, 9, 1036-1056. https://doi.org/10.4236/msa.2018.913075

Received: October 30, 2018

Accepted: December 18, 2018

Published: December 21, 2018

Copyright (c) 2018 by authors and Scientific Research Publishing Inc. This work is licensed under the Creative Commons Attribution International License (CC BY 4.0).

http://creativecommons.org/licenses/by/4.0/

\begin{abstract}
A CO $2 / \mathrm{NaAlO}_{2} / \mathrm{H}_{2} \mathrm{O}$ absorption-reaction system was adopted to prepare nano aluminum trihydrate (ATH) particles for cables use in a rotating packed-bed (RPB) reactor (Phase I). The Taguchi experimental design was used to give an orthogonal array, $\mathrm{L}_{9}\left(3^{4}\right)$. The parameters were the speed of rotation $(\mathrm{A})$, gas-liquid flow rate ratio (B), aging temperature (C) and aging time (D), each having three levels. According to the signal/noise $(S / N)$ ratio analysis, optimum condition for BET area $\left(S_{w}\right)$ was found to be A3B3C1D1, while the parameter significance was DABC. Empirical formula for $S_{w}$ was also obtained and discussed. Subsequently, the optimum size $(10.7 \mathrm{~nm})$ of ATH powders was used to blend with the matrix including plastics and additives (Phase II) for characterization further. The examination of composite materials showed that the limiting oxygen index (LOI) was higher than 28 , indicating an excellent fire-retarding property. The results also showed that the LOI for nano ATH is higher than that bought from the market, while the fire-retarding grade examination (UL-94 test) for both ATHs was found to be of a V-0 grade. In addition, the mechanical properties for nano ATH were measured prior to using the ATH from the market.
\end{abstract}

\section{Keywords}

Absorption, Aluminum Trihydrate, Rotating Packed Bed, Taguchi

\section{Introduction}

Flame retardants are used in many fields for products such as cell phones, carpets and insulating sheets, to prevent them from being burnt or to at least slow down a fire in an emergency [1]. Most fires and casualties in recent years resulted from inflammable polymers and the toxic gas released during a fire [2]. 
Therefore, the selection of flame retardants is a big problem. Flame retardants can be divided into groups identified by their halogen base, phosphor base, nitrogen base, borium base, silicon base, antimony base, metal oxide or hydroxide [3] [4] [5] [6]. The most familiar flame retardant on the market is the halogen compound because the halogen can react with a free radical quickly, gradually implementing an excellent flame retardant effect. However, a halogen compound damages the atmosphere, reduces the ozonosphere, releases corrosive acidic gases and generates toxic dioxin. Therefore, with the rise in environmental considerations, various countries have made strict regulations governing current flame retardant materials including being halogen-free, low smoke and heavy metal-free [7] [8] [9]. An inorganic metal hydroxide as the flame retardant in polymers does not produce toxic gas during combustion. The product from combustion harms the environment, whereas a metal oxide performs an endothermic reaction in combustion and releases water vapor; the polymer surface temperature is reduced and the metal oxide covering the polymer surface forms a protection layer to obstruct flammable gas, so as to retard the flame [10] [11] [12].

At present, the most familiar inorganic metal hydroxides are magnesium hydroxide $(\mathrm{MH})$ and aluminum trihydrate (ATH) [13] [14]. Both of these have filling, flame retardant and smoke suppression functions. They are the major inorganic flame retardants used in present industrial circles. ATH decomposes at about $180^{\circ} \mathrm{C}$, absorbing a considerable amount of heat in the process and giving off water vapor. In addition to behaving as a fire retardant, it is very effective as a smoke suppressant in a wide range of polymers, especially in polyesters, acrylics, ethylene vinyl acetate, epoxies, PVC and rubber [15].

In comparison to other flame retardants, the preparation, use and discarding processes for ATH are free of hazardous material, and they have low smoke generation, low corrosivity and low toxicity [7] [8] [10] [11] [12] [14] [16]. ATH is selected as the flame retardant for this experiment because its maximum dehydration temperature $\left(250.4^{\circ} \mathrm{C}\right)$ is lower than the maximum thermal degradation temperature of linear low density polyethylene (LLDPE) $\left(380.1^{\circ} \mathrm{C}\right)$, and the flame retardant should release moisture earlier than the substrate, so as to successfully perform the flame retardant effect. The maximum dehydration temperature $\left(396.2^{\circ} \mathrm{C}\right)$ of $\mathrm{MH}$ is higher than the substrate, so it cannot perform the flame retardant effect [17] [18]. Alternatively, ATH loses water gradually at $210^{\circ} \mathrm{C}-370^{\circ} \mathrm{C}$ to form an alumina powder. The dehydration reaction releases 2.5 portions of hydrate water resulting in a great deal of heat being absorbed, so that the ATH reduces the burning temperature of the substrate, i.e. the "cooling technique" of flame retardant technology, showing its smoke suppression effect [19].

As ATH is a typical polar inorganic material, it has poor affinity with a nonpolar organic polymer. The interfacial bonding force is weak, so that the workability and physical mechanical properties of the composite with this flame retar- 
dant are degraded. The ATH of nano-particles can enhance the interfacial interaction, and ATH is dispersed in plastic substrates more uniformly, so as to improve the mechanical and flame retardant properties of blend composition [20] [21] [22] [23].

The methods for preparing ATH include the Bayer precipitation method, the Bayer addition method, and aqueous caustic and aluminum chloride syntheses. The sodium aluminate solution and $\mathrm{CO}_{2}$ synthesis, e.g. a high-gravity rotating packed bed (HGRPB), can prepare nano-scale ATH [24] [25] [26] [27]. In addition, synthesis of ATH was explored recently by Chen et al. [28] who obtained pseudo-boehmite nanoparticles with a direct precipitation method and the transparent dispersions of boehmite nanoparticles was obtained by a following hydrothermal treatment. The formation mechanism of ATH was also discussed in this paper. Jiao et al. [29] found that $\mathrm{Al}^{3+} / \mathrm{AlO}_{2}^{-}$ratio can affect the initial $\mathrm{pH}$ and hence the ATH morphologies. As we know, sodium aluminate is an important commercial inorganic chemical. It works as an effective source of aluminum hydroxide, which is also known as hydrated alumina, aluminum hydrate or alumina tri-hydrate (ATH), for many industrial and technical applications. The reaction can be expressed as:

$$
\mathrm{CO}_{2}(g) \rightarrow \mathrm{CO}_{2}(a q)
$$

when carbon dioxide is excess:

$$
\mathrm{NaAlO}_{2}(a q)+\mathrm{CO}_{2}(a q)+\mathrm{H}_{2} \mathrm{O}(a q) \rightarrow \mathrm{Al}(\mathrm{OH})_{3}(s)+\mathrm{NaHCO}_{3}(a q)
$$

when carbon dioxide is less:

$$
2 \mathrm{NaAlO}_{2}(a q)+\mathrm{CO}_{2}(a q)+3 \mathrm{H}_{2} \mathrm{O}(a q) \rightarrow 2 \mathrm{Al}(\mathrm{OH})_{3}(s)+\mathrm{Na}_{2} \mathrm{CO}_{3}(a q)
$$

It was found that factors affecting the formation of ATH using HGRPB were carbonation of sodium aluminate (SA), temperature, speed, SA concentration, $\mathrm{G} / \mathrm{L}$ ratio and terminal $\mathrm{pH}$ [25]. Other factors affecting the formation of ATH were precipitation time, soda content, additives, amount of seed and surface area of the seed [30]. The gravity field generated by the high speed centrifugal force of HGRPB can tear and thin the liquid film, however, the gas-liquid mass transfer rate was good, the reaction time was short, and the composite powder size distribution was narrow, so the nano-scale powder could be prepared [26] [27].

As we known, there have not been any extensive studies on the effects of process parameters on the particle size and specific surface area of ATH product for rotating packed bed reactors. In addition, no ATH flame-retardant data was avaiable. Therefore, it would be highly beneficial for the optimization of reaction processes to produce a high quality ATH. Taguchi statistical analysis was performed to get the relative importance of each parameter and to obtain the optimal condition. This study used HGRPB to prepare nano-scale ATH, and used the Taguchi method to find the optimum conditions for preparing ATH. Afterwards, the nano-ATH produced under optimum conditions and the commercially available ATH powder were mixed with a linear low density polyethylene (LLDPE), an ethylene ethyl acrylate copolymer (EEA), zinc borate ( $\mathrm{ZnB})$ and 
nanomontmorillonite (MMT) to obtain cable materials in a fixed proportion, respectively, so comparison of the flame resistance, mechanical properties and thermal analysis of the composites after mixing the nano-scale and commercially available powders was possible. In order to reach the purpose of this work, a framework was proposed, as shown in Figure 1. Two phases were adopted: Phase I was designed for the preparation of ATH, while Phase II was designed for the preparation and characterization of the cable materials.

Steps to accomplish the purpose of this work were:

1) The Taguchi method was used to look for optimum conditions for preparing nano-ATH. The particle size, grain size, powder morphology and thermal analysis were analyzed.

2) ATH, prepared under the optimum conditions and the commercially available ATH, were mixed in the same proportions, respectively. The flame retardancy, mechanical properties and thermal analysis of the composites were compared.

\section{Experimental Feature}

\subsection{Experimental Design for the Synthesis of ATH}

In order to reduce the experimental cost, an experimental design for the synthesis of ATH was required. Factors adopted here were centrifugal speed of RPB (A), gas liquid flow rate ratio (B), aging temperature (C) and aging time(D), each having three levels, as shown in Table 1. According to the Taguchi method, the orthogonal array is listed in Table 2 for experimental design. This reduces the experimental number from $3^{4}=81$ to $\mathrm{L}_{9}\left(3^{4}\right)=9$. In addition, parameter significance and optimum condition could be obtained by using signal/noise (S/N) analysis.

\subsection{Materials and Method for the Synthesis of ATH}

The starting materials used for the synthesis of $\mathrm{ATH}$ were $\mathrm{NaAlO}_{2}$ and $\mathrm{CO}_{2}$ gas.
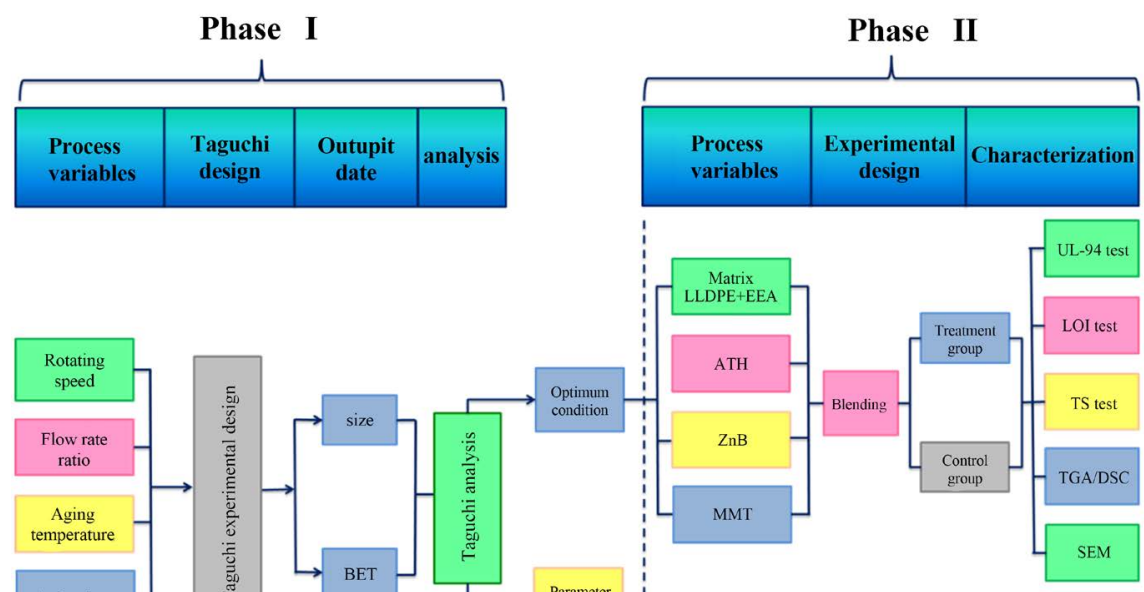

Figure 1. A framework for preparation and characterization of cable materials. 
Table 1. Factors and levels for the synthesis of ATH.

\begin{tabular}{cccc}
\hline \multirow{2}{*}{ Factor } & \multicolumn{3}{c}{ Level } \\
\cline { 2 - 4 } & 1 & 2 & 3 \\
$\mathrm{~A}$ & $1000 \mathrm{rpm}$ & $1500 \mathrm{rpm}$ & $2000 \mathrm{rpm}$ \\
$\mathrm{B}$ & 0.6 & 0.8 & 1.0 \\
$\mathrm{C}$ & $50^{\circ} \mathrm{C}$ & $60^{\circ} \mathrm{C}$ & $70^{\circ} \mathrm{C}$ \\
$\mathrm{D}$ & $1 \mathrm{hr}$ & $2 \mathrm{hr}$ & $3 \mathrm{hr}$ \\
\hline
\end{tabular}

Table 2. Orthogonal array for the synthesis of ATH.

\begin{tabular}{lllll}
\hline No. & A & B & C & D \\
\hline A1 & 1 & 1 & 1 & 1 \\
A2 & 1 & 2 & 2 & 2 \\
A3 & 1 & 3 & 3 & 3 \\
A4 & 2 & 1 & 2 & 3 \\
A5 & 2 & 2 & 3 & 1 \\
A6 & 2 & 3 & 1 & 2 \\
A7 & 3 & 1 & 3 & 2 \\
A8 & 3 & 2 & 1 & 3 \\
A9 & 3 & 3 & 2 & 1 \\
\hline
\end{tabular}

All of the chemicals used were of an analytical grade (Alfa Aesar). The experimental apparatus of the RPB is shown schematically in Figure 2, which was similar to that reported in the literature [31] [32]. The apparatus consisted of a rotating packed bed, pumps, flow meters, speed controller, water bath and reservoir. The rotating packed bed contained wired packing with several layers. A known volume and concentration of reactant $\left(2 \mathrm{M} \mathrm{NaAlO}_{2}\right.$ solution) was taken and fed into the reactor at a desired rotating speed from the top of the reactor through the action of tubing pumps. The reactant temperature was controlled at $25^{\circ} \mathrm{C}$. In addition, a desired flow rate of $\mathrm{CO}_{2}$ gas was fed into the reactor. The reactant was pumped through the distributer into the rotating packed bed and made contact with $\mathrm{CO}_{2}$ gas, where the primary step of the reaction occurred. Then, the product slurry flowed out of the reacting chamber and was collected in the product reservoir. The time from the beginning of this process to the end is termed the reaction process time when the solution $\mathrm{pH}$ reached 12. At the end of operation, the slurry was withdrawn and heated to the desired temperature level for the aging process. After the aging process, the slurry was filtered and rinsed with acetone, and the cake was dried in a hot air oven for one hour. The dried powders were analyzed by XRD to identify the composition of the product. The decomposition temperatures of the dried powders were determined by means of XRD (Rigaku, D/MAX2200) analysis. Then, the ATH powders were characterized further by means of TGA/DSC (TA, SDT-Q600), SEM (JEOL, JSM-6500F) and BET (PMI, BET 201-APCW) analyses. 


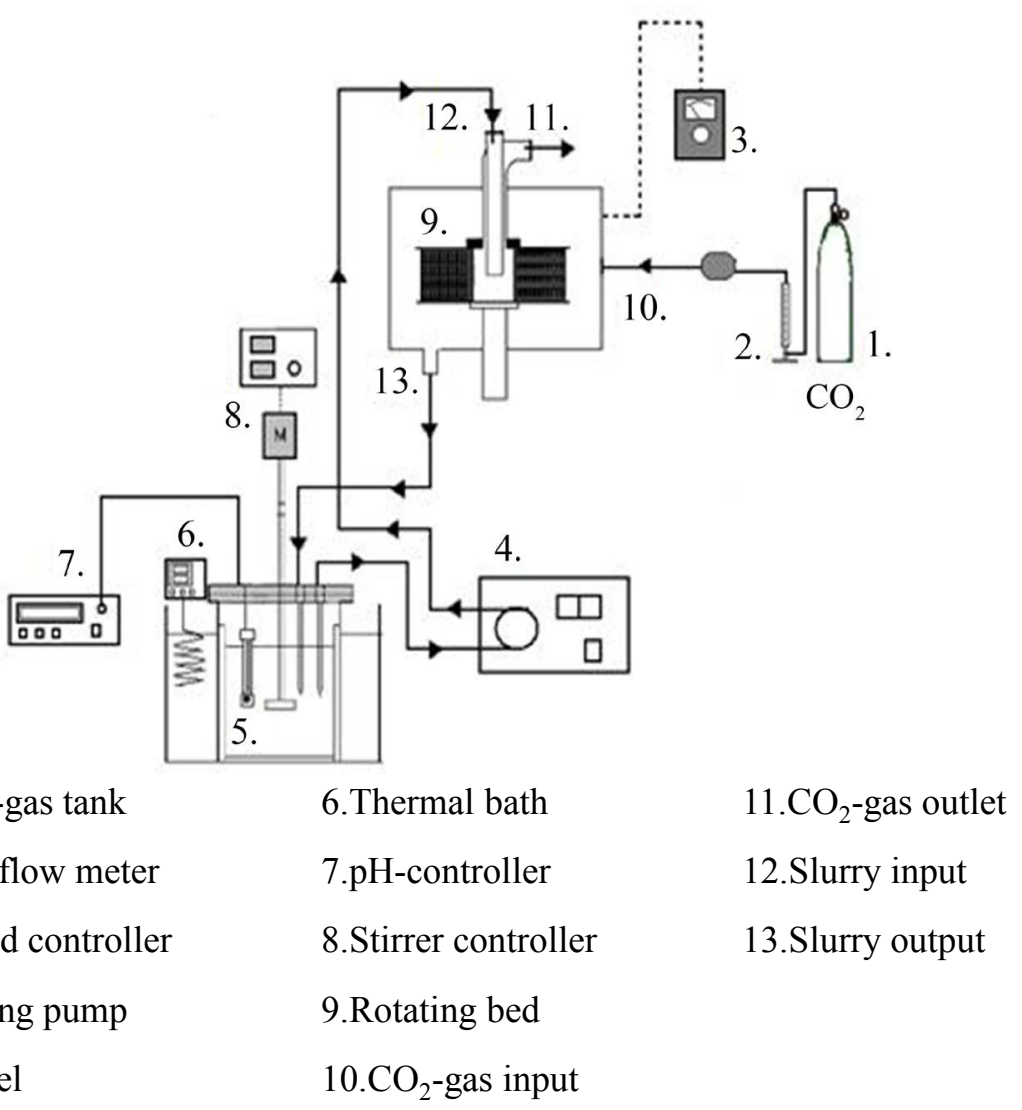

Figure 2. A RPB device for preparation of nano-scale ATH; please see the reference [31] [32].

\subsection{Blending Tests for Flame Retardant Cable Materials}

Materials for blending tests, ATH, MMT, ZB, EEA and LLDPE, were employed by using a twin screw (C. W. Brabender, Laboratory Double Sigma Blender) at a working temperature of $170^{\circ} \mathrm{C}$. In order to carry out the blending test, three series ( $\mathrm{A}, \mathrm{B}$ and $\mathrm{C}$ ) of tests were explored here, as shown in Table 3. Series A was only matrix LLDPE tested for comparison. Series B and C used the same ingredients except ATH; Series B's ingredients were obtained in the market, while Series C's ingredients were obtained in this work. After blending, the composite materials were used in thermal compression to prepare specimens for tests, including mechanical property and flame retardant tests, as shown in Figure 3. The former was measured by a tensile strength mechine (QC-TECH, CTS-2KN); the latter was measured by the limiting oxygen index (LOI) (Suga Test Instrument Co. Ltd., ON-1) and UL-94 test (UL-1). In addition, the thermal properties and dispersion of composite materials were examined by TGA/DSC and SEM analyses, respectively.

\section{Results and Discussion}

\subsection{Morphology of Nano-ATH Crystals}

The SEM photographs shown in Figure 4(a) and Figure 4(b) indicate irregular 
Table 3. Contribution of materials in blending tests at different series. ${ }^{\star} \mathrm{ATH}$ was gotten in the market.

\begin{tabular}{ccccccc}
\hline \multirow{2}{*}{ Series } & & \multicolumn{3}{c}{ Matrix } & \multicolumn{3}{c}{ Flame retardant agents } \\
\cline { 3 - 7 } & No & $\begin{array}{c}\text { LLDPE } \\
(\mathrm{wt} \%)\end{array}$ & $\begin{array}{c}\text { EEA } \\
(\mathrm{wt} \%)\end{array}$ & $\begin{array}{c}\text { ATH } \\
(\mathrm{wt} \%)\end{array}$ & $\begin{array}{c}\text { ZnB } \\
(\mathrm{wt} \%)\end{array}$ & $\begin{array}{c}\text { Clay } \\
(\mathrm{wt} \%)\end{array}$ \\
\hline A & A0 & 100 & 0 & 0 & 0 & 0 \\
& B1 & 40 & 10 & 40 & 10 & 0 \\
B $^{*}$ & B2 & 40 & 10 & 40 & 9 & 1 \\
& B3 & 40 & 10 & 40 & 7 & 3 \\
& B4 & 40 & 10 & 40 & 5 & 5 \\
& C1 & 40 & 10 & 40 & 10 & 0 \\
& C2 & 40 & 10 & 40 & 9 & 1 \\
& C3 & 40 & 10 & 40 & 7 & 3 \\
& C4 & 40 & 10 & 40 & 5 & 5 \\
\hline
\end{tabular}

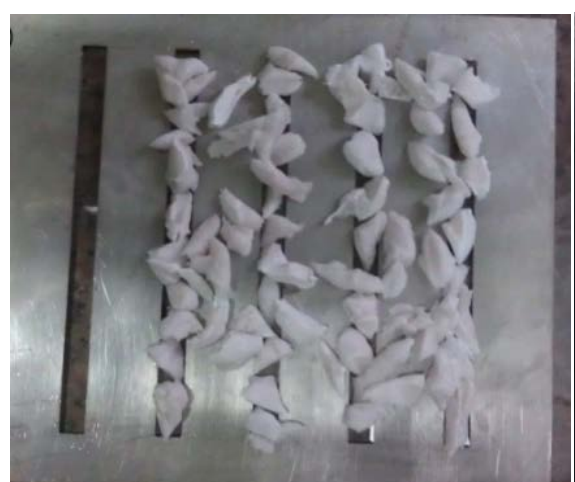

(a)

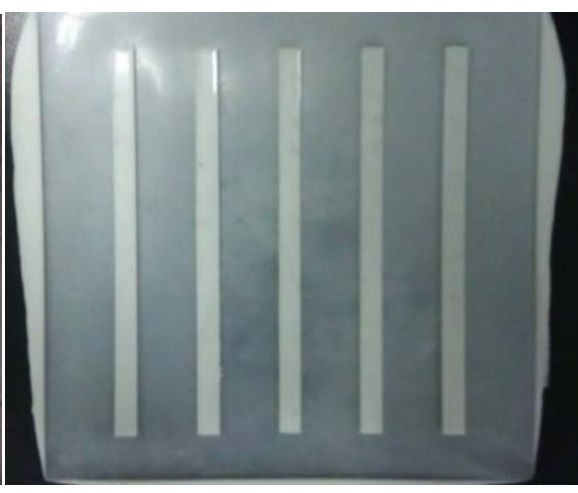

(b)

Figure 3. Specimens prepared using thermal compression. (a) before compression; (b) after compression.

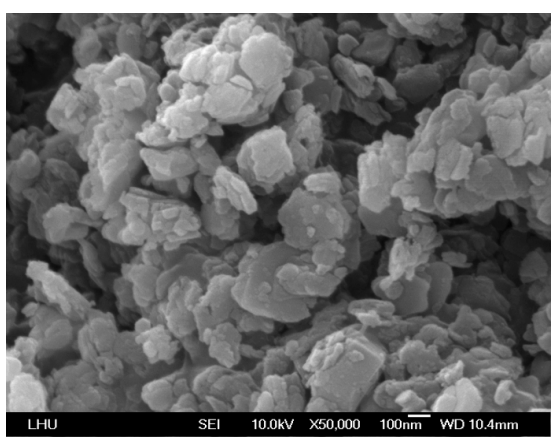

(a)

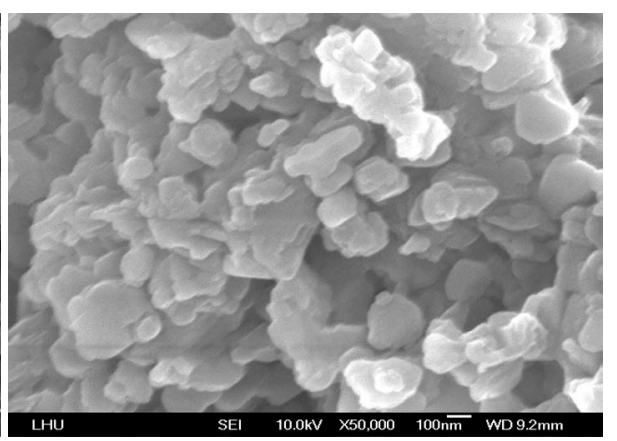

(b)

Figure 4. Typical ATH SEM photographs from different runs. (a) Sample A2; (b) Sample A7.

crystal forms with the two forms prepared in this study. The two pictures show similar irregular shapes. The pictures also show aggregates with tiny particles. Therefore, it is hard to determine crystal size from particle size analyzer. Due to 
this, the crystal size can be determined by using XRD analysis and BET measurement further.

\subsection{BET Specific Surface Area of Nano-ATH}

The specific surface areas obtained were in the range of $44.75-237.06 \mathrm{~m}^{2} / \mathrm{g}$ as shown in Table 4 . The BET specific area can be used to calculate the particle size. The equation is:

$$
\mathrm{d}_{\mathrm{BET}}=\frac{6}{\rho S_{w}}
$$

The calculated sizes were in the range of $10.82-57.30 \mathrm{~nm}$.

In order to effectively determine $S_{w}$ and understand the factors affecting $S_{w}$, the relationship of $S_{w}$ and variables can be correlated by using linear regression. The result was:

$$
S_{W}=0.04534 \exp \left(\frac{2544.05}{T}\right) N^{0.1081} R^{0.8046} t^{-0.7235}
$$

The regression error is $7.48 \%$. The result showed that $S_{w}$ increased with an increase in $N(\mathrm{~A})$ and $R(\mathrm{~B})$, while it decreased with an increase in $T(\mathrm{C})$ and $t(\mathrm{D})$. Moreover, this equation can be used to predict the $S_{w}$ and hence $\mathrm{d}_{p}$, when the conditions are given.

\subsection{Confirmation of Nano-ATH Crystals from XRD Analysis}

ATHs obtained here can be characterized by using XRD analysis. Figure 5 shows the XRD patterns for night runs. As compared with a standard card, the patterns showed two ATH forms, i.e. Bayerite ( $\beta$-phase) and Gibbsite ( $\alpha$-phase), mixed together. The Bayerite form includes major peaks at $(0,0,1),(1,1,0),(1$, $1,-1)$ and $(1,3,-1)$; while the Gibbsite form shows peaks at $(0,0,2),(0,2,1),(3$, $1,1)$ and $(2,0,2)$. This indicates that the two forms provide different crystalline structures. The major peak with an ( $\mathrm{h} \mathrm{k} \mathrm{l}$ ) value of $\left(\begin{array}{lll}0 & 0 & 2\end{array}\right)$ at $18.45^{\circ}$ is the characteristic of monoclinic ATH as per JCPDS card number 76-1782.

Table 4. BET specific area and crystal size for both methods.

\begin{tabular}{cccc}
\hline No. & Condition & $S_{w}\left(\mathrm{~m}^{2} / \mathrm{g}\right)$ & $\mathrm{d}_{\mathrm{BET}}(\mathrm{nm})$ \\
\hline 1 & A1B1C1D1 & 181.70 & 14.11 \\
2 & A1B2C2D2 & 119.11 & 21.53 \\
3 & A1B3C3D3 & 87.05 & 29.46 \\
4 & A2B1C2D3 & 44.75 & 57.30 \\
5 & A2B2C3D1 & 95.91 & 26.73 \\
6 & A2B3C1D2 & 109.25 & 23.47 \\
7 & A3B1C3D2 & 139.32 & 18.41 \\
8 & A3B2C1D3 & 85.84 & 29.87 \\
9 & A3B3C2D1 & 237.06 & 10.82
\end{tabular}




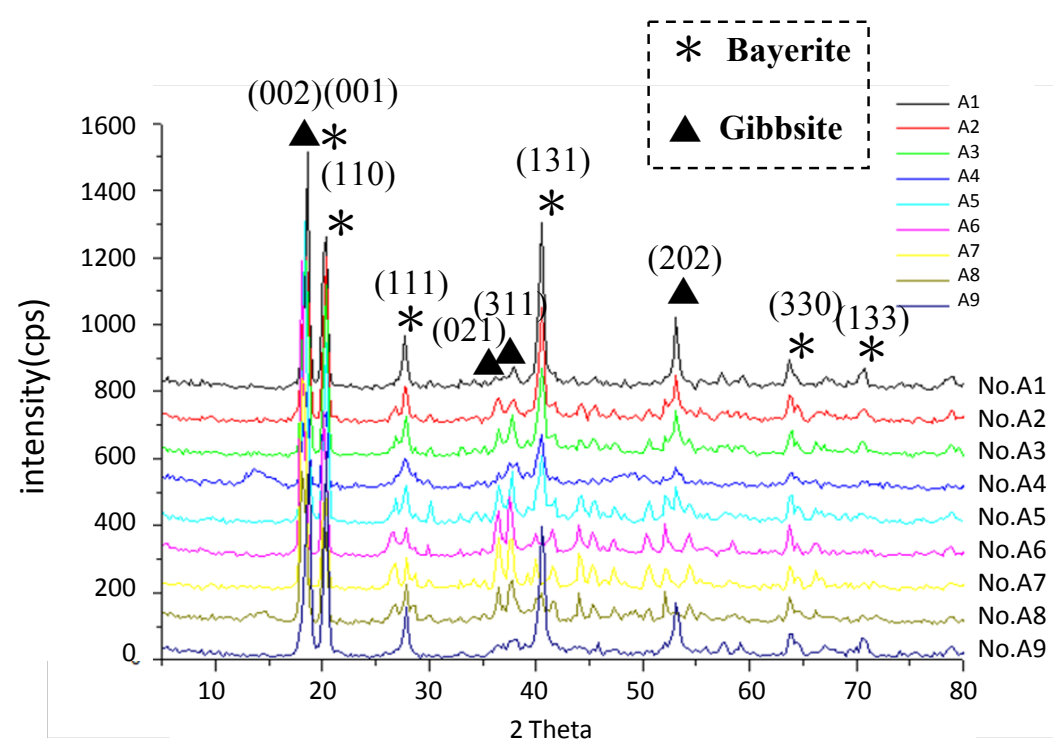

Figure 5. XRD patterns for ATHs prepared in here.

For comparison, mean crystal size was also determined using XRD analysis with the aid of FWHM (full width at half maximum). The size, $d_{\text {XRD }}$, can be estimated using the Scherer equation:

$$
\mathrm{d}_{\mathrm{XRD}}=\frac{K \lambda}{\beta \cos \theta}
$$

where $K$ is a dimensionless shape factor (a typical value of 0.9 ), $\beta$ is the line broadening at the full width at half maximum (FWHM), $\lambda$ is the X-ray wavelength and $\theta$ is the Bragg angle (in degrees). Table 5 lists the estimated sizes of ATH particles, which was close to that determined by BET areas. Figure 6 was a plot of $d_{\mathrm{XRD}}$ vs. $\mathrm{d}_{\mathrm{BET}}$ for comparing both methods.

\subsection{Thermal Property of Nano-ATH Crystals}

The thermal property of ATH was also examined, as shown in Figure 7(a)-(c). In Figure 7(a), the heat flow of ATH (No. 3) changed with the heating temperature. From DSC analysis, the enthalpy $(\Delta \mathrm{H})$ and maximum endothermic temperature $\left(T_{e n}^{* *}\right)$ could be determined simultaneously. Figure $7(\mathrm{~b})$ showed the DSC spectra of each ATH obtained. On the other hand, Figure 7 (c) shows the TGA measurement spectra showing the weight loss during heating and giving the maximum decomposition temperature $\left(T_{d}^{*}\right)$. All data obtained is listed in Table 6 showing the effect of particle size. It can be found that the $\Delta H$ is higher at a smaller size since a smaller particle gives a higher surface area resulting in a higher $\Delta \mathrm{H}$. In addition, the weight loss for a smaller particle is higher than for a larger one due to the smaller particle having a larger surface area, which favors water loss.

\subsection{Taguchi Analysis}

The $S / N$ ratio is calculated according to the larger-the-better value and the 
Table 5. Nano ATH crystal size estimated using Scherer equation.

\begin{tabular}{lccc}
\hline No. & FWHM & $2 \theta$ & $\mathrm{d}_{\text {XRD }}(\mathrm{nm})$ \\
\hline A1 & 0.55 & 18.314 & 15.89 \\
A2 & 0.37 & 18.314 & 26.64 \\
A3 & 0.302 & 18.187 & 37.64 \\
A4 & 0.258 & 18.244 & 55.39 \\
A5 & 0.307 & 18.230 & 36.45 \\
A6 & 0.427 & 18.776 & 21.80 \\
A7 & 0.383 & 18.287 & 25.32 \\
A8 & 0.42 & 18.413 & 22.27 \\
A9 & 0.442 & 18.314 & 20.81 \\
\hline
\end{tabular}

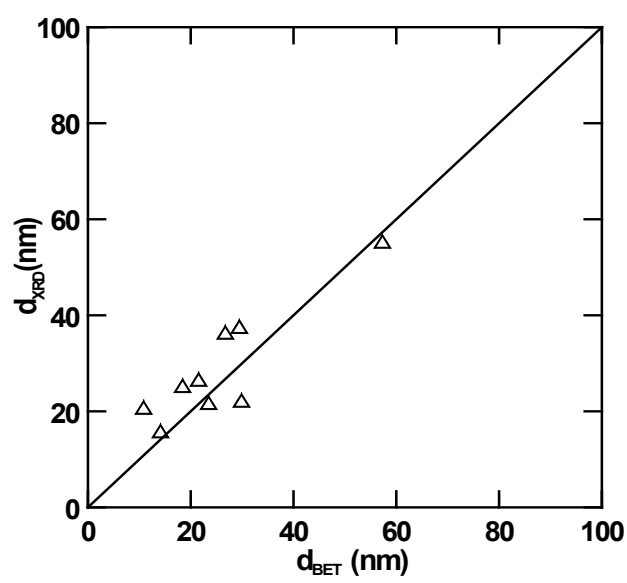

Figure6. A plot of $\mathrm{d}_{\mathrm{XRD}}$ versus $\mathrm{d}_{\mathrm{BET}}$ showing the reliable methods for both.

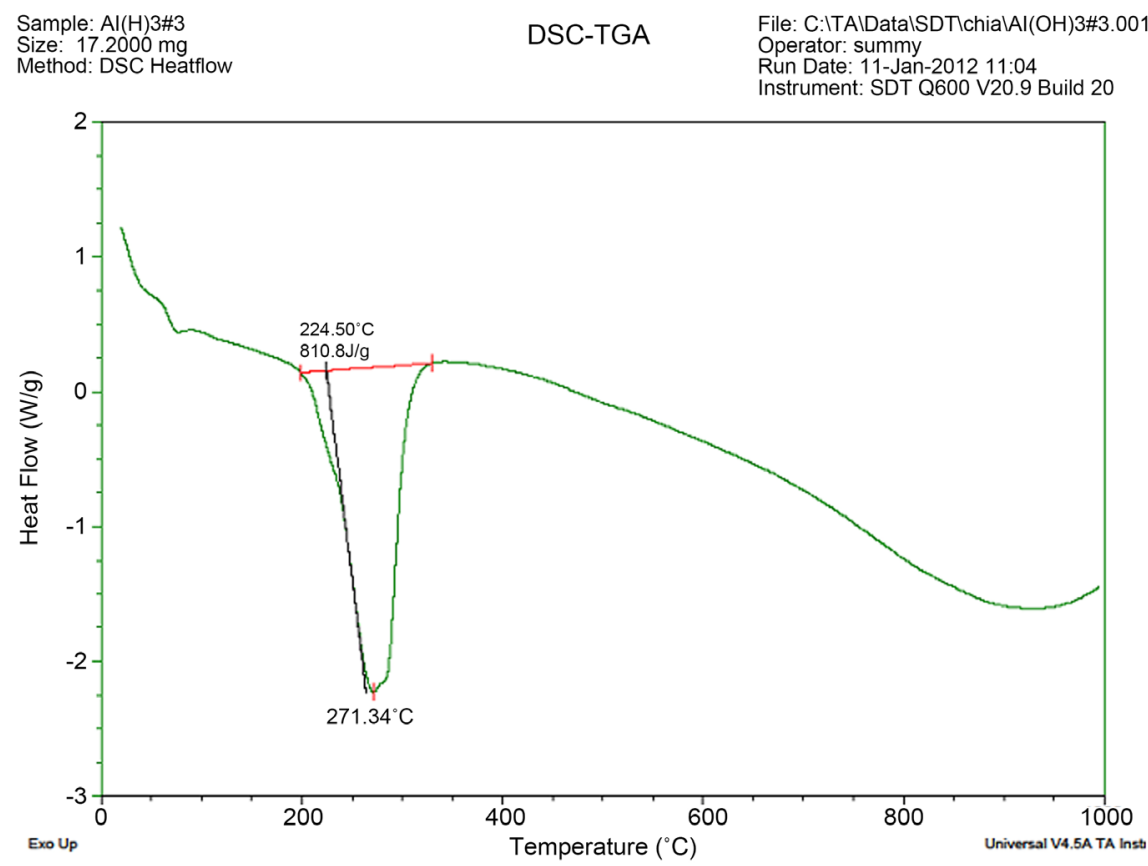

(a) 


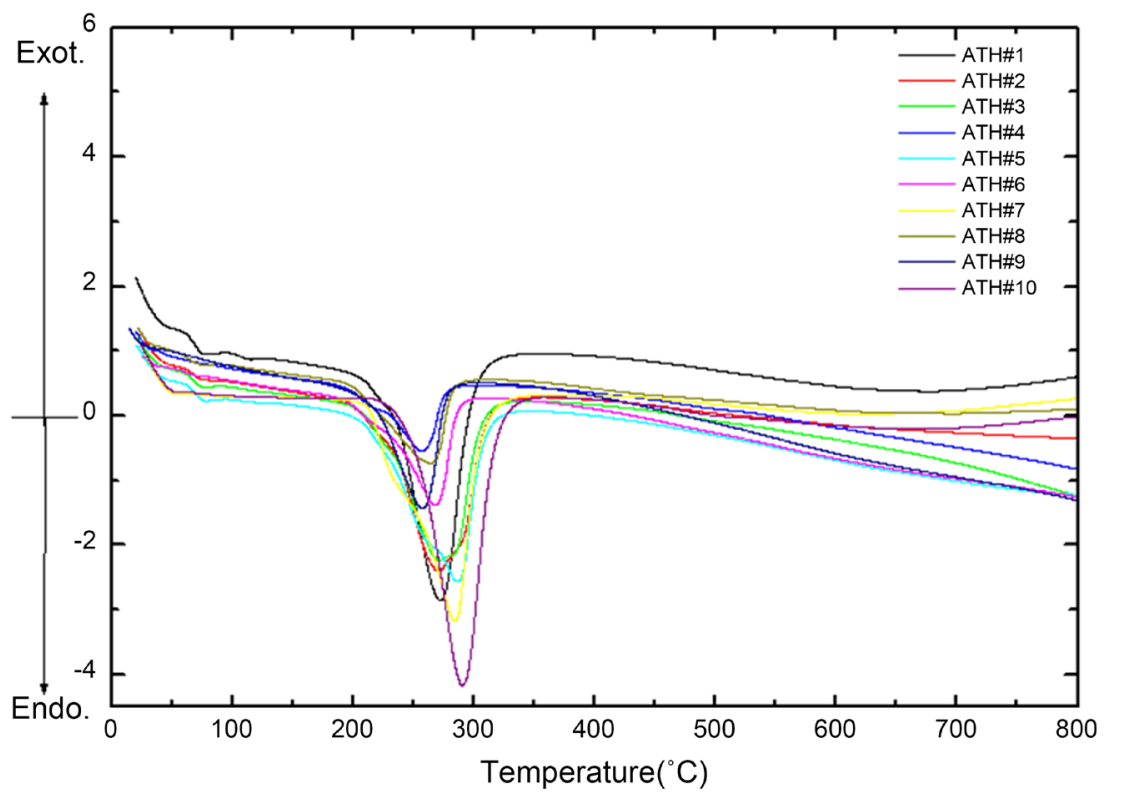

(b)

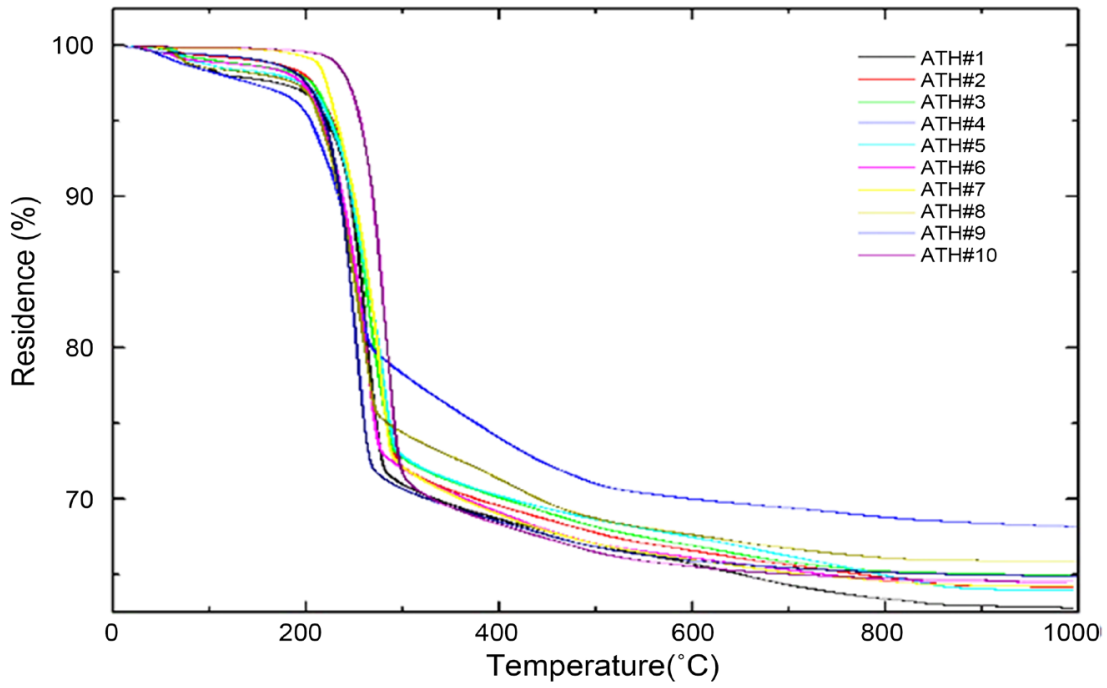

(c)

Figure 7. TGA/DSC analyses for ATHs showing thermal property of each ATH. (a) Sample A3; (b) DSC analysis for all samples; (c) TGA analysis for all samples

Table6. Thermal data of nano-ATH from TGA/DSC analysis.

\begin{tabular}{cccccc}
\hline & $T_{d}^{*}\left({ }^{\circ} \mathrm{C}\right)$ & $T_{e n}^{* *}\left({ }^{\circ} \mathrm{C}\right)$ & $\Delta \mathrm{H}(\mathrm{J} / \mathrm{g})$ & Weight loss $(\%)$ & $\mathrm{d}_{\text {BET }}(\mathrm{nm})$ \\
\hline A1 & 285.17 & 272.17 & 919.0 & 64.27 & 14.11 \\
A2 & 296.11 & 270.43 & 865.3 & 65.44 & 21.53 \\
A3 & 291.37 & 271.34 & 810.8 & 65.83 & 29.46 \\
A4 & 267.68 & 257.11 & 495.3 & 69.41 & 57.30 \\
A5 & 296.11 & 286.10 & 865.1 & 66.21 & 26.73 \\
A6 & 278.34 & 267.66 & 848.0 & 65.26 & 23.47
\end{tabular}




\begin{tabular}{cccccc} 
Continued & \multicolumn{7}{l}{} \\
\hline A7 & 290.19 & 283.99 & 895.6 & 65.61 & 18.41 \\
A8 & 274.79 & 263.82 & 744.6 & 66.73 & 29.87 \\
A9 & 268.86 & 257.11 & 1056.0 & 65.09 & 10.82 \\
A10 & 302.04 & 290.33 & 1085.0 & 64.98 & 10.70 \\
\hline
\end{tabular}

$T_{d}^{*}=$ maximum decomposition temperature; $T_{e n}^{* *}$ = maximum endothermic temperature.

smaller-the-better value from the data obtained in the final stage. The sequences of importance and optimum conditions are found by using the $S / N$ ratiocalculations where $\mathrm{d}_{\mathrm{XRD}}$ takes the smaller-the-better value, and $S_{w}$ takes the larger-the-better value as shown below:

$$
\frac{S}{N}=-10 \times \log \left(\frac{1}{n} \sum_{1}^{n} z_{i}^{2}\right)
$$

and

$$
\frac{S}{N}=-10 \times \log \left(\frac{1}{n} \sum_{1}^{n} \frac{1}{z_{i}^{2}}\right)
$$

where $n$ is the number of data evaluated and $z_{i}$ is the data presented at the $i^{\text {th }}$ level.

According to Equation (7) the smaller-the-better $S / N$ ratio analysis for size is shown in Table 7. The three levels were used in here, which was the common levels (3 - 4 levels) adopted in the Taguchi experimental design [29]. The results show that the optimum condition is $\mathrm{A} 3 \mathrm{~B} 3 \mathrm{C} 1 \mathrm{D} 1$, see bracket; and the sequence of parameter importance is $\mathrm{CDAB}$. Alternatively, the $S / N$ ratio analysis for $S_{w}$ (the larger-the-better) was also explored. According to Equation (8), the estimated values are presented in Table 8 . It can be found that the optimum condition is $\mathrm{A} 3 \mathrm{~B} 3 \mathrm{C} 1 \mathrm{D} 1$, which is the same as that in $\mathrm{d}_{\mathrm{XRD}}$; while the sequence of parameter importance is $\mathrm{DABC}$, which is different from that obtained in $\mathrm{d}_{\mathrm{XRD}}$. This indicates that $\mathrm{D}$ and $\mathrm{A}$ are major factors for $S_{w}$ while $\mathrm{C}$ and D are major factors affecting $d_{\mathrm{XRD}}$.

The optimum condition, A3B3C1D1 (No. 10), for both cases was also carried out for verification. Characterization of No. 10 for the X-ray spectra and SEM photographs was needed and is shown in Figure 8. The result for $d_{\mathrm{XRD}}$ was $15.25 \mathrm{~nm}$ and for $S_{w}$ was $239.72 \mathrm{~m}^{2} / \mathrm{g}$, leading to a $10.70 \mathrm{~nm} \mathrm{BET}$ size. Due to this, the optimum conditions were confirmed further as compared with the values in Table 5. In addition, $S_{w}$ can be evaluated using Equation (8), giving $271.6 \mathrm{~m}^{2} / \mathrm{g}$ in $S_{w}$ at the optimum condition of A3B3C1D1. The value is higher than $239.72 \mathrm{~m}^{2} / \mathrm{g}$, indicating that Equation (8) is reliable.

\subsection{Characterization of Flame Retardant Materials}

In order to compare the effects of different ATH sources on the blending test, additions of A10 and market ATHs in the blended materials were explored. Sample A10 was prepared under optimum conditions. The particle sizes for both 
Table 7. $S / N$ analyses for $\mathrm{d}_{\mathrm{XRD}}$ to find optimum condition and parameter importance.

\begin{tabular}{ccccc}
\hline Level & A & B & C & D \\
\hline 1 & -28.02 & -28.99 & $(-25.92)$ & $(-27.21)$ \\
2 & -30.96 & -28.90 & -29.91 & -27.78 \\
3 & $(-27.13)$ & $(-28.22)$ & -30.27 & -31.11 \\
Delta & 3.83 & 0.77 & 4.36 & 3.90 \\
Rank & $\mathbf{3}$ & 4 & 1 & 2 \\
\hline
\end{tabular}

Table 8. $S / N$ analyses for $S_{W}$ to find optimum condition and parameter importance.

\begin{tabular}{ccccc}
\hline Level & A & B & C & D \\
\hline $\mathbf{1}$ & 41.83 & 40.36 & $(41.54)$ & $(44.11)$ \\
$\mathbf{2}$ & 37.81 & 39.94 & 40.68 & 41.72 \\
$\mathbf{3}$ & $(43.02)$ & $(42.35)$ & 40.44 & 36.83 \\
Delta & 5.21 & 2.41 & 1.11 & 7.28 \\
Rank & 2 & 3 & 4 & 1 \\
\hline
\end{tabular}

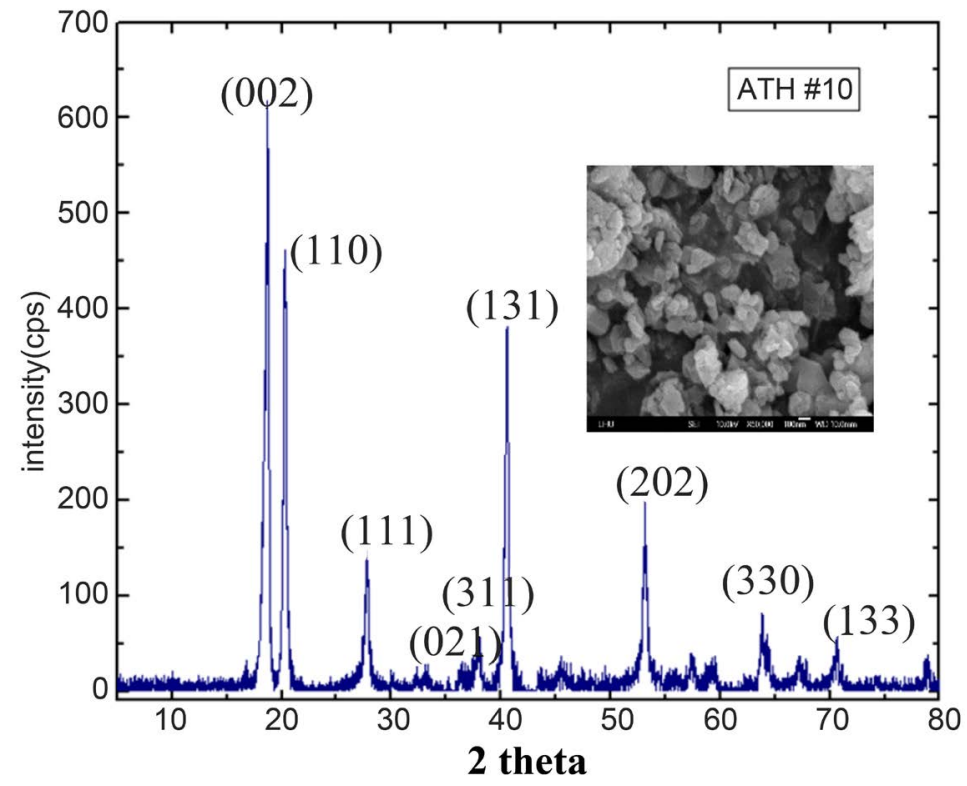

Figure 8. XRD spectra and morphology of ATH obtained for No.10.

are $10.70 \mathrm{~nm}$ and $29.11 \mathrm{~nm}$ for A10 and market ATH, respectively. In addition, the effects of MMT on characterizations for both cases include mechanical properties, LOI, the UL-94 test, TGA/DSC and SEM.

\subsubsection{Mechanical Property for Blended Materials}

The effects of MMT and a type of ATH on the mechanical properties were investigated. Figure 9 (a)-(c) presented the effect of both on the tensile strength (TS), elongation at the break (EB) and tensile modulus (E). It was found that mechanical properties among them for ATH prepared in our study were higher 


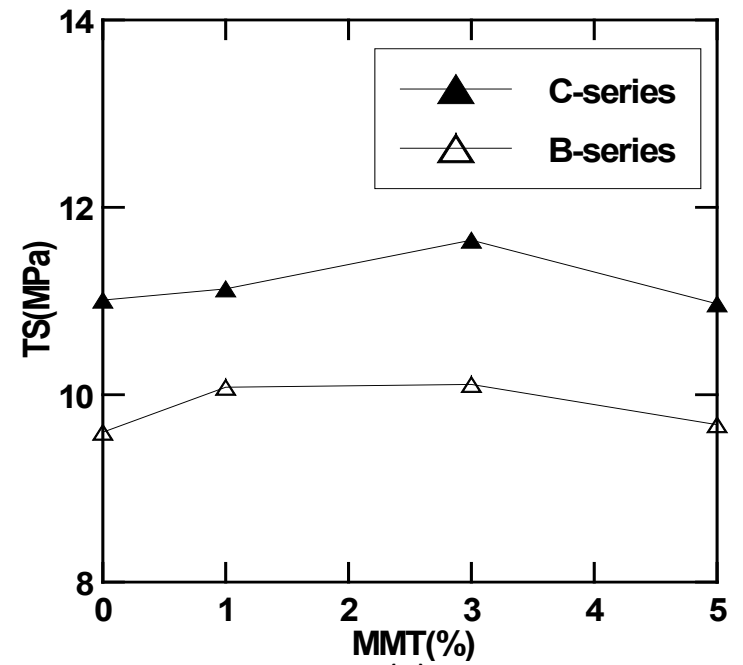

(a)

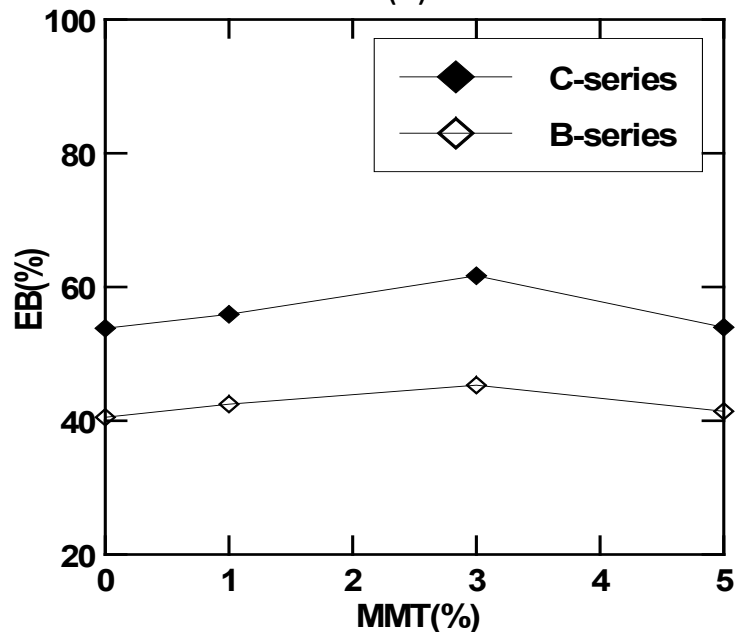

(b)

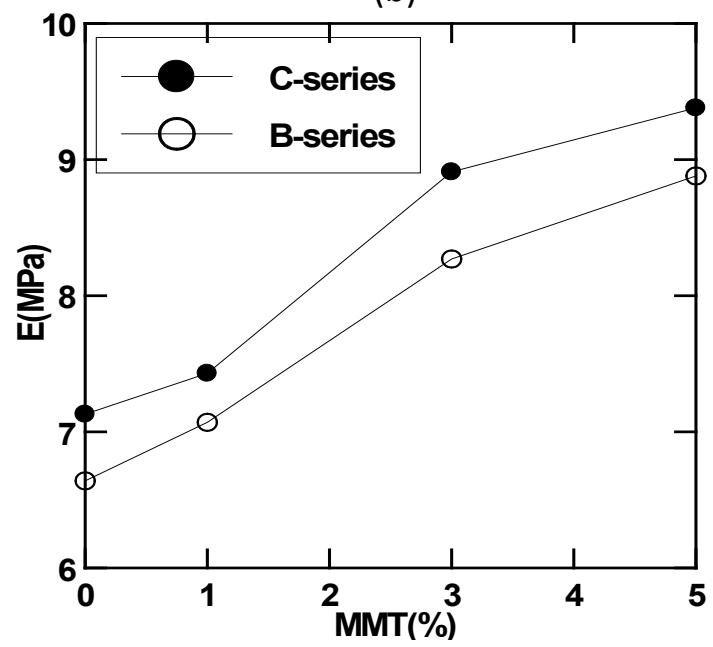

(c)

Figure 9. Effect of MMT on the mechanical property of composite materials.

than those for product bought in the market. The possible reason is the effect of size. In addition, the effect of MMT on the TS showed that TS increased with an 
increase in MMT at about 3\%; then it decreased with MMT, as shown in Figure 9(a). A similar result for EB is shown in Figure 9(b). On the other hand, E increased with an increase in MMT, as shown in Figure 9(c), indicating that the addition of MMT can improve the mechanical strength of E. However, the TS and EB for pure LLDPE were 18.56 Mpa and 551.92\%, respectively. The values were much higher than those for blended materials due to the presentation of ATH in the matrix. This indicated that the addition of flame retardant materials resulted in the decrease in mechanical properties. Therefore, how to control the ingredients of composite materials while obtaining a good flame retardant with excellent mechanical properties becomes a significant focus in future applications.

\subsubsection{Flame Retardant Test for Blended Materials}

There are two methods used to evaluate a flame retardant: one is the LOI method and the other is the UL-94 method. Figure 10 shows the effect of MMT in both cases. It was found that LOI increased with an increase in MMT, while the LOI in Series C was higher than that in Series B. The values of the LOI showed that the materials were exhibited as sparingly flammable when LOI was greater than 26, which was higher than 22.5 for pure LLDPE, indicating the effect of the addition of retardant materials. From this viewpoint, the flame retardant test showed that ATH becomes an effective material as a flame retardant.

In addition, three major levels in the UL-94 test, i.e. $\mathrm{V}-2, \mathrm{~V}-1$ and $\mathrm{V}-0$, were used to examine, in which V-0 was the highest level among them. The results for different samples are shown in Table 9. Comparing the two series showed that the flame time for Series $C$ was always less than for Series B, indicating the effect of ATH size on the flame time because the specific surface area for $\mathrm{C}$ is high enough to release more vapor, decreasing the burning temperature and hence, reducing the burning time. All cases passed the minimum UL-94 test except for

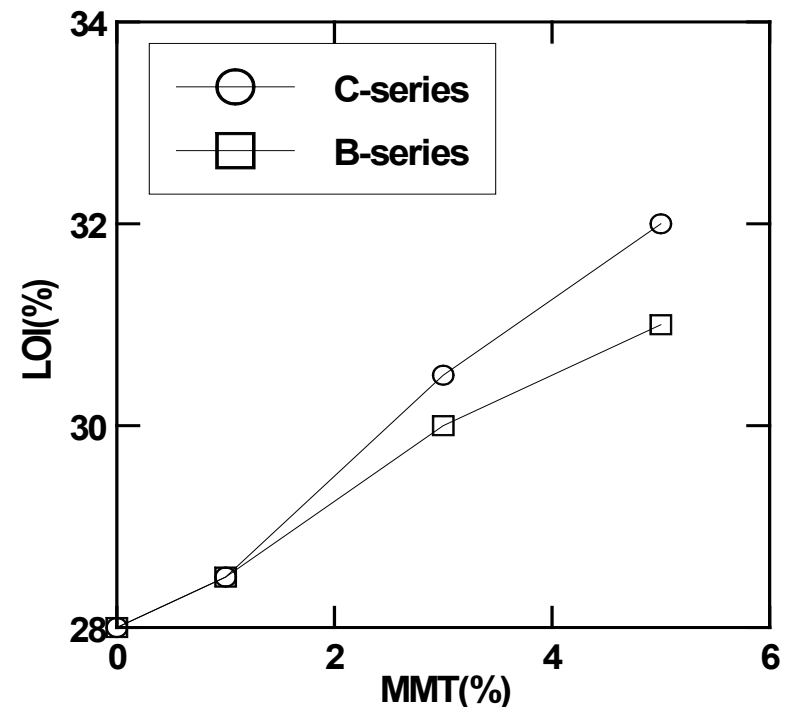

Figure 10. Effect of MMT on LOT. 
Table 9. UL-94 test for various samples.

\begin{tabular}{ccccc}
\hline Series & No. & $\begin{array}{c}\text { UL-94 } \\
\text { level }\end{array}$ & $\begin{array}{c}\text { Flame time for a total } \\
\text { of 5 specimens (Sec) }\end{array}$ & $\begin{array}{c}\text { Drip of flaming particles } \\
\text { that ignite }\end{array}$ \\
\hline & B1 & V-2 & 183 & $\sqrt{ }$ \\
B & B2 & Fail & 472 & $\sqrt{ }$ \\
& B3 & V-2 & 103 & $\sqrt{ }$ \\
& B4 & V-0 & 11 & \\
C1 & V-2 & 169 & \\
& C2 & Fail & 463 & \\
& C3 & V-2 & 89 & \\
& C4 & V-0 & 8 & \\
\hline
\end{tabular}

$\mathrm{B} 2$ and $\mathrm{C} 2$ because the blending materials were not uniformly distributed in the matrix. However, B3 and C3 passed the V-2 test, while B4 and C4 all passed the V-0 test. At 5\% MMT, ATH, MMT and ZnB have uniform distribution in the matrix, enhancing more water vapor and absorbing more energy when burning. Therefore, this shows that an excellent flame retardant property was observed as demonstrated with SEM photographs in Figure 11.

\subsubsection{Thermal Property of Blended Retardant Materials}

Thermal data for flame retardant composite materials were measured using a TGA/DSC machine, as shown in Figure 12(a)-(b) for a typical example in Series C. Measured data was determined and is listed in Table 10, including melting points, decomposition temperatures and weight loss at $600^{\circ} \mathrm{C}$. In addition, pure LLDPE and EEA were also measured, as shown in the first two rows. The values in $T_{d}$ are much higher than for Series B and C. In addition, $T_{m}$ and $T_{d}$ for Series $\mathrm{C}$ are slightly less than for Series B, showing the effect of size. However, $T_{m}$ and $T_{d}$ for both cases decreased with an increase in MMT, supporting the LOI test, as shown in Figure 10 because the flame retardant in the matrix was decomposed before the matrix, creating an effective flame retardant for the flame retardant composite materials. In general, the decomposition temperatures for ATH were between $200^{\circ} \mathrm{C}-300^{\circ} \mathrm{C}$, resulting in weight loss in the composite materials. In addition, the $T_{d}$ for Series B and C were around $288^{\circ} \mathrm{C}-290^{\circ} \mathrm{C}$, showing the effect of the formation of $\mathrm{Al}_{2} \mathrm{O}_{3}$ on the matrix.

\section{Conclusion}

Nano ATH-based flame-retardant materials for cables were successfully prepared. Synthesis of nano-ATH crystals and the blending of retardant materials in the matrix (LLDPE/EEA) were effectively explored using an RPB reactor and a twinscrew extruder. The obtained BET areas of nano ATH were in the range of $44.75-237.06 \mathrm{~m}^{2} / \mathrm{g}$, corresponding to the sizes of $15.89-55.39 \mathrm{~nm}$, which are close to that determined by the Scherer equation and XRD data. Results showed that the sizes of nano ATH crystals can be controlled by adjusting the parameters. 
Table 10. Thermal data obtained for TGA/DSC analyses.

\begin{tabular}{cccc}
\hline & $T_{m}\left({ }^{\circ} \mathrm{C}\right)$ & $T_{d}\left({ }^{\circ} \mathrm{C}\right)$ & Weight loss at $600^{\circ} \mathrm{C}(\mathrm{Wt} . \%)$ \\
\hline Pure LLDPE & 123.60 & 456.16 & -0.38 \\
Pure EEA & 100.41 & 452.54 & -0.26 \\
B1 & 122.20 & 291.58 & 30.26 \\
B2 & 122.06 & 287.80 & 33.77 \\
B3 & 121.95 & 285.24 & 36.46 \\
B4 & 121.66 & 283.91 & 36.46 \\
C1 & 122.10 & 289.85 & 30.26 \\
C2 & 121.71 & 286.53 & 34.55 \\
C3 & 121.51 & 284.21 & 35.98 \\
C4 & 121.11 & 282.73 & 36.55 \\
\hline
\end{tabular}

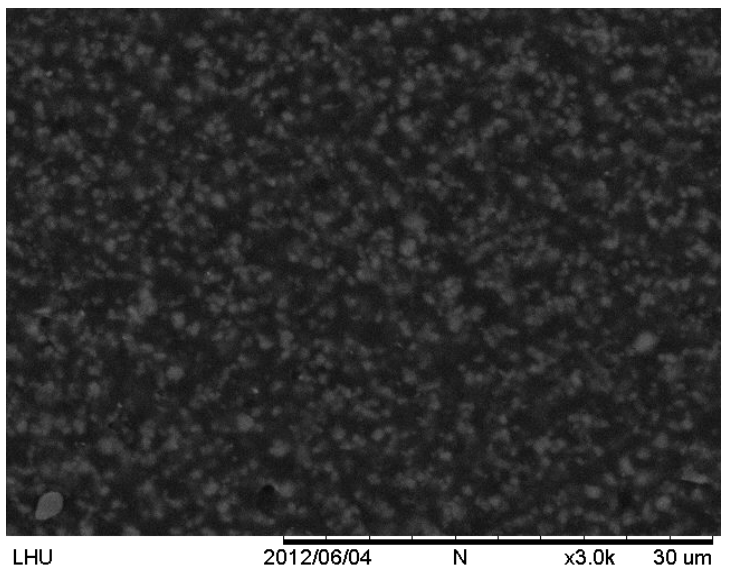

Figure 11. SEM image for No. 10 showing uniform distribution of flame retardant materials in the matrix.

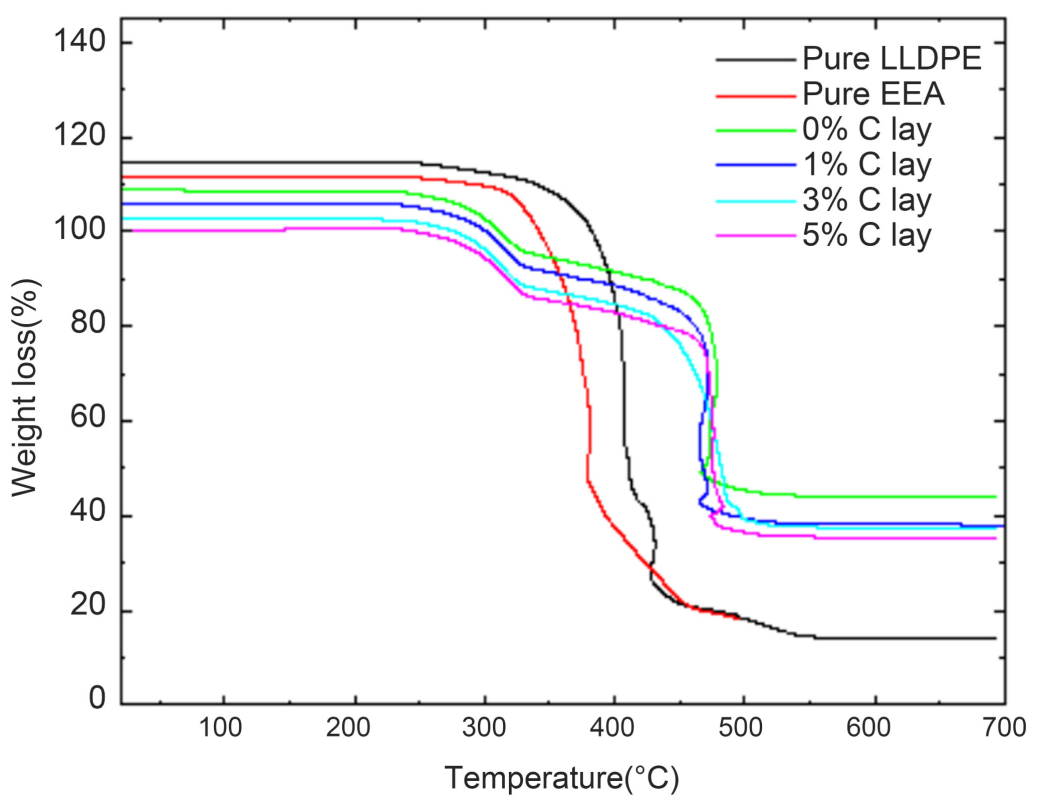

(a) 


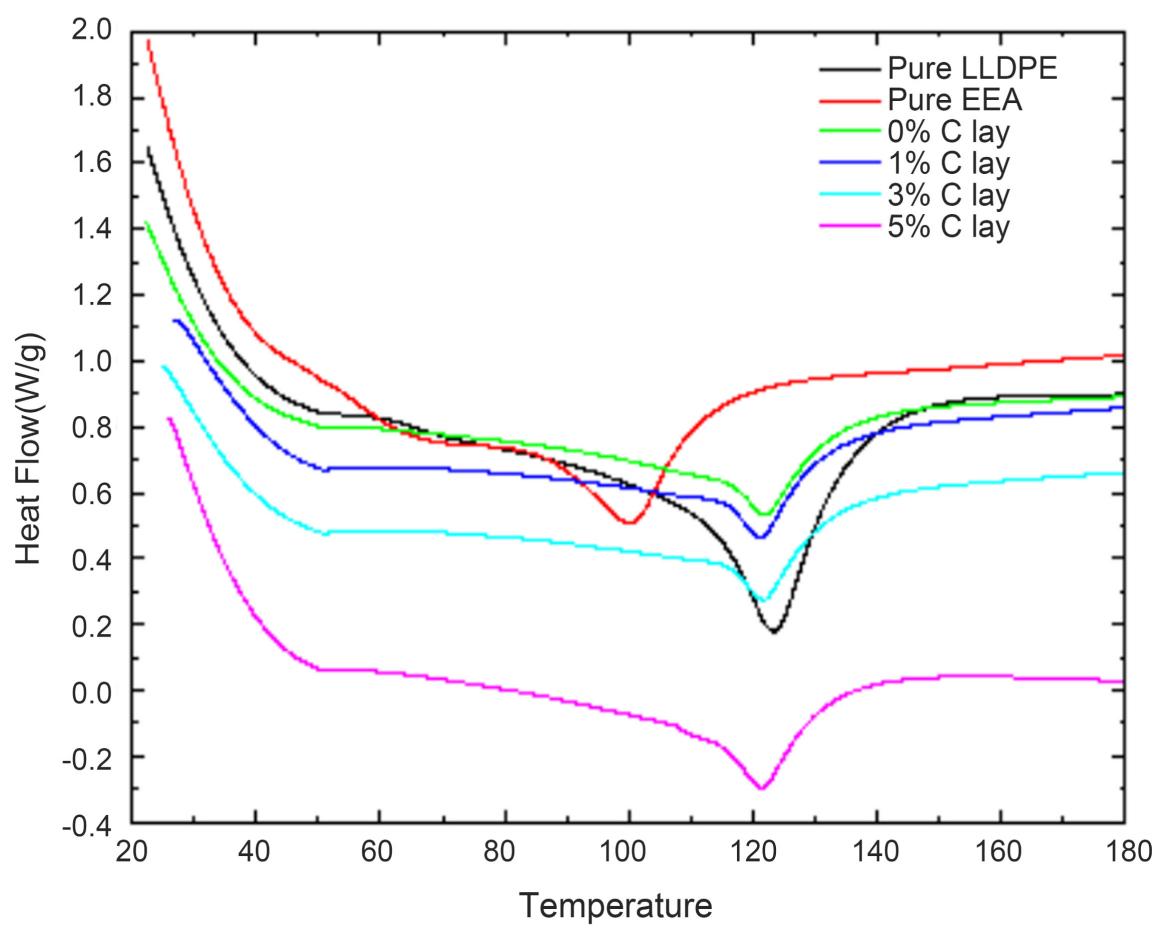

(b)

Figure 12. Thermal data analysis for composite materials. (a)TGA analysis; (b)DSC analysis.

The optimum condition A3B3C1D1 in $S_{w}$ was successfully verified for the "larger-the-better", obtaining $239.72 \mathrm{~m}^{2} / \mathrm{g}$ in $S_{w}$, which is $271.6 \mathrm{~m}^{2} / \mathrm{g}$ as predicted by the correlation equation. In addition, the parameter importance shows that D and A are major factors affecting $S_{w}$, while B and C are minor factors. All of them supported that the data obtained here is reliable and the $S_{w}$ expression is useful. Blending materials found that nano-ATH for mechanical and flame-retardant properties tests were superior to those available in the market. SEM photographs show that dispersion of ATH/MMT/ZnB in the polymer matrix is uniform and shows an excellent property. Finally, the process creates an opportunity to capture $\mathrm{CO}_{2}$ for some industries.

\section{Acknowledgements}

We thank the financial support from Ministry of Science and Technology in Taiwan, MOST 106-2221-E-262-015.

\section{Conflicts of Interest}

The authors declare no conflicts of interest regarding the publication of this paper.

\section{References}

[1] Lynch, T.J., Tong, C.D. and Riley, C.D. (2003) Advances in ATH Benefit Composite Products. Reinforced Plastices, 9, 44-46. 
[2] (2017). https://en.wikipedia.org/wiki/Grenfell_Tower_fire

[3] Adschiri, T., Hakuta, Y. and Sue, K. (2001) Hydrothermal Synthesis of Metal-Oxide Nanoparticles at Supercritical Conditions. Journal of Nanoparticle Research, 3, 227-235. https://doi.org/10.1023/A:1017541705569

[4] Bourbigot, S., Le bras, M., Leeuwendal, R., Shen, K.K. and Schubert, D. (1999) Recent Advances in the Use of Zinc Borates in Flame Retardancy of EVA. Polymer Degradation and Stability, 64, 419-425. https://doi.org/10.1016/S0141-3910(98)00130-X

[5] Balabanovich, A.L. (2001) Fire Retardance in Polyamide-6, the Effects of Red Phosphorus and Radiation-Induced Cross-Links. Fire and Materials, 25, 179-184. https://doi.org/10.1002/fam.768

[6] Li, Y. and Wang, W.D. (2004) The Effect of Decabromodiphenyl Oxide and Antimony Trioxide on the Flame Retardation of Ethylene-Propylene-Diene Copolymer/Polypropylene Blends. Polymer Degradation and Stability, 86, 69-73. https://doi.org/10.1016/j.polymdegradstab.2004.01.015

[7] Kim, D.W. (2001) Preparation of High Dispersion Aluminum Hydroxide. Journal of Dispersion Science and Technology, 38, 267-273.

[8] Lu, S.Y. and Ian, H. (2002) Recent Developments in the Chemistry of Halogen-Free Flame Retardant Polymers. Progress in Polymer Science, 27, 1661-1712. https://doi.org/10.1016/S0079-6700(02)00018-7

[9] Rothon, R.N. and Hornsby, P.R. (1996) Flame Retardant Effects of Magnesium Hydroxide. Polymer Degradation and Stability, 54, 383-385. https://doi.org/10.1016/S0141-3910(96)00067-5

[10] Qiu, L.Z., Lu, J.P., Xie, R.C. and Qu, B.J. (2003) Structural Characteristics and Flame-Retardant Properties of Nano Sized Magnesium Hydroxide. Chinese Journal of Semiconductors, 24, 81-84.

[11] Hornsby, P.R. (1994) Application of Magnesium Hydroxide as a Fire Retardant and Smoke-Suppressing Additive for Polymers. Fire and Materials, 18, 269-276. https://doi.org/10.1002/fam.810180502

[12] Hornsby, P.R. and Watson, C.L. (1990) A Study of the Mechanism of Flame Retardance and Smoke Suppression in Polymers Filled with Magnesium Hydroxide. Polymer Degradation and Stability, 30, 73-87. https://doi.org/10.1016/0141-3910(90)90118-Q

[13] Sangcheol, K. (2003) Flame Retardancy and Smoke Suppression of Magnesium Hydroxide Filled Polthylene. Journal of Polymer Science Part B: Polymer Physics, 41, 936-944. https://doi.org/10.1002/polb.10453

[14] Wang, D.G., Guo, F., Chen, J.G., Shao, L., Liu, H. and Zhang, Z.T. (2007) A Two-Step Way to Synthesize Nano Inner-modified Aluminum Trihydroxide. Colloids and Surfaces A: Physicochemical and Engineering Aspects, 293, 201-209. https://doi.org/10.1016/j.colsurfa.2006.07.030

[15] Wu, D.F., Wu, L., Wu, L.F. and Zhang, M. (2006) Rheology and Themal Stability of Polylactide/Clay Nanocomposites. Polymer Degradation and Stability, 91, 3149-3155. https://doi.org/10.1016/j.polymdegradstab.2006.07.021

[16] Ramazani, S.A.A., Rahimi, A., Frounchi, M. and Radman, S. (2008) Investigation of Flame Retardancy and Physical-Mechanical Properties of Zinc Borate and Aluminum Hydroxide Propylene Composites. Materials \& Design, 29, 1051-1056. https://doi.org/10.1016/j.matdes.2007.04.003

[17] Wang, D.G., Guo, F., Chen, J.F. and Zhang, Z.T. (2008) Precipitation of Nano Alu- 
minum Trihydroxide by High Gravity Reactive Precipitation. Chemical Engineering Journal, 121, 109-114. https://doi.org/10.1016/j.cej.2006.05.016

[18] Lu, H., Hu, Y., Yang, L., Wang, Z., Chen, Z. and Fan, W.C. (2004) Study of the Fire Performance of Magnesium Hydroxide Sulfate Hydrate Whisker Flame Retardant Polyethylene. Macromolecular Materials and Engineering, 289, 984-989. https://doi.org/10.1002/mame.200400165

[19] https://www.hubermaterials.com/userfiles/files/PFDocs/Huber\%20Non-Halogen\%2 0Fire\%20Retardant\%20Additives.pdf

[20] Cárdenas, M.A., Garcíalópez, D., Gobernadomitre, I., Merino, J.C., Paster, J.M., Martinez, J.D., Barbeta, J. and Calveras, D. (2008) Mechanical and Fire Retardant Properties of EVA/Clay/ATH Nano Composites-Effect of Particle Size and Surface Treatment of ATH Filler. Polymer Degradation and Stability, 93, 2032-2037. https://doi.org/10.1016/j.polymdegradstab.2008.02.015

[21] Almeidapinto, U., Visconte, L.L.Y., Gallo, J. and Nunes, R.C.R. (2000) Flame Retardancy in Thermoplastic Polyurethane Elastomers (TPU) with Mica and Aluminum Trihydrate (ATH). Polymer Degradation and Stability, 69, 257-260. https://doi.org/10.1016/S0141-3910(00)00047-1

[22] Ye, Y., Ding, P., Zhang, M. and Qu, B. (2008) Synergistic Effects of Exfoliated LDH with Some Halogen-Free Flame Retardants in LDPE/EVA/HFMH/LDH Nano Composites. Journal of Applied Polymer Science, 107, 3694-3701. https://doi.org/10.1002/app.27526

[23] Naskar, K., Mohanty, S. and Nando, G.B. (2007) Development of Thin-Walled Halogen-Free Cable Insulation and Halogen-Free Fire-Resistant Low-Smoke Cable-Sheathing Compounds Based on Polyolefin Elastomer and Ethylene Vinyl Acetate Blends. Journal of Applied Polymer Science, 104, 2839-2848. https://doi.org/10.1002/app.25870

[24] Chen, J.C., Shao, L., Guo, F. and Wang, X.M. (2003) Synthesis of Nano-Fibers of Aluminum Hydroxide in Novel Rotating Packed Bed Reactor. Chemical Engineering Science, 58, 569-575. https://doi.org/10.1016/S0009-2509(02)00581-X

[25] Wang, D.G., Guo, F., Chen, J.F., Liu, H. and Zhang, Z.T. (2006) Preparation of Nano Aluminum Trihydroxide by High Gravity Reactive Precipitation. Chemical Engineering Journal, 121, 109-114. https://doi.org/10.1016/j.cej.2006.05.016

[26] Chen, J.F., Wang, Y.H., Guo, F., Wang, X.M. and Zheng, C. (2000) Synthesis of Nanoparticles with Novel Technology: High-Gravity Reactive Precipitation. Industrial \& Engineering Chemistry Research, 39, 948-954. https://doi.org/10.1021/ie990549a

[27] Chen, J.F., Zheng, C. and Chen, G.T. (1996) Interaction of Macro and Micro Mixing on Particle Size Distribution in Reactive Precipitation. Chemical Engineering Science, 51, 1957-1966. https://doi.org/10.1016/0009-2509(96)00053-X

[28] Chen, B., Wang, J.X., Wang, D., Zebg, X.F., Clarke, S.M. and Chen, J.F. (2018) Synthesis of Transparent Dispersions of Aluminum Hydroxide Nanoparticles. Nanotechnology, 29, Article ID: 305605.

[29] Jiao, W., Wu, X., Xue, T., Li, G., Wang, W., Wang, Y., Wang, Y.M., Tang, Y. and He, M.Y. (2016) Morphology Controlled Growth of Nanosized Boehmite with Enhanced Aspect Ratios in an Organic Additive-Free Cationic-Anionic Double Hydrolysis Method. Crystal Growth \& Design, 16, 5166-5173. https://doi.org/10.1021/acs.cgd.6b00723

[30] Pradhan, J.K., Gochhayat, P.K., Bhattacharya, I.N. and Das, S.C. (2001) Study on the Various Factors Affecting the Quality of Precipitated Non-Metallurgical Alu- 
mina Trihydrate Particles. Hydrometallurgy, 60, 143-153.

https://doi.org/10.1016/S0304-386X(00)00196-1

[31] Ng, C.M., Chen, P.C. and Manickam, S. (2012) Green High-Gravitational Synthesis of Silver Nanoparticles Using a Rotating Packed Bed Reactor (RPBR). Industrial \& Engineering Chemistry Research, 51, 5375-5381. https://doi.org/10.1021/ie201795u

[32] Chen, P.C. and Lin, J. (2016) Effect of Solution Condition on the Precipitation of Nano-Cupric Oxide by Using a High Gravity Process. JTICE, 59, 514-520. 